\title{
Pituitary Adenoma Confined Within the Pituitary Stalk: A Case Report and Literature Review
}

\author{
Jae Hyun Park ${ }^{1}$, Tae Hoon Roh $^{1}$, Jang-Hee Kim ${ }^{2}$, Se-Hyuk Kim ${ }^{1}$ \\ ${ }^{1}$ Department of Neurosurgery, Ajou University Hospital, Ajou University College of Medicine, Suwon, Korea \\ ${ }^{2}$ Department of Pathology, Ajou University Hospital, Ajou University College of Medicine, Suwon, Korea
}

Received: September 23, 2021

Accepted: September 27, 2021

Corresponding Author:

Author Tae Hoon Roh, M.D., Ph.D.

Department of Neurosurgery,

Ajou University College of

Medicine 164, World cup-ro,

Yeongtong-gu, Suwon 16499,

Korea

Tel: +82-31-219-5230

Fax: +82-31-219-5238

E-mail: throh@ajou.ac.kr
Pituitary adenomas within the pituitary stalk, without pituitary gland involvement, are extremely rare. To date, only six cases of pituitary adenomas confined to the pituitary stalk have been reported in English publications; all of which were functional tumors suspected to originate from the pars tuberalis. Herein, we report a case of a non-functioning pituitary adenoma thought to originate from and confined within the pituitary stalk. The patients had normal hormone levels during the initial evaluation and underwent surgery using the endonasal trans-sphenoidal approach. Histopathological examination was performed to confirm the diagnosis. A careful review of the literature was also performed.

Keywords: Pituitary neoplasms; Adenoma; Pituitary gland; Hormone; Surgery

\section{INTRODUCTION}

Pituitary adenomas are among the most common intracranial tumors, accounting for $10-15 \%$ of all intracranial tumors ${ }^{1}$. Nonfunctioning pituitary adenomas require surgical management when they are expected to show symptoms attributed to mass ef$\mathrm{fect}^{2}$. The majority of pituitary adenomas originate from the anterior pituitary gland; that is, majority of pituitary adenomas grow within the sella turcica. Furthermore, pituitary adenomas may dilate the diaphragm and extend beyond the suprasellar area ${ }^{3}$. On rare occasions, they may be present in extra-sellar sites not continuous with the pituitary gland, with or without an adenoma in the pituitary gland. First described by Erdheim in 1909 and predominantly described in case reports, such cases may be referred to as ectopic pituitary adenomas (EPAs) ${ }^{4}$.

Though most pituitary adenomas are found in continuity with the gland, such ectopic forms of pituitary adenomas are usually found in the sphenoid sinus, clivus, suprasellar space, nasopharynx, and cavernous sinus. Pituitary adenomas strictly confined to the pituitary stalk are extremely rare ${ }^{5,6)}$. Herein, we report a case of a nonfunctioning pituitary adenoma strictly confined to the pituitary stalk.

\section{CASE REPORT}

A 57-year-old woman was referred to our clinic with an incidental finding of a suprasellar mass. The patient was asymptomatic, with blood tests and hormone levels within normal ranges. Computed tomography revealed an 8-mm, high-density, contrast-enhanced mass in the pituitary stalk. Additionally, magnetic resonance imaging showed a mass of heterogeneous signal intensity on both T1WI and T2WI within the pituitary stalk, protruding toward the 3rd ventricle. The MR image also showed suspected intratumoral hemorrhage and prominent heterogeneous enhance- 
ment under contrast. (Fig. 1)

A tumor of pituitary origin was suspected; differential diagnoses of lymphoma, craniopharyngioma, germ cell tumor, and granular cell tumor were considered. For pathologic confirmation, extended endoscopic endonasal trans-sphenoidal surgery was planned for the approach.

The operative findings confirmed the absence of pituitary gland involvement. The surgical field extended to the supra-diaphragm area, which revealed a thickened pituitary stalk. The lesion was curetted by a vertical incision and subsequently sucked out, preserving the anatomy of the pituitary gland and stalk. The tumor was well confined within the stalk and was completely removed. (Fig. 2) Postoperative MRI showed no residual tumor. The pathologic study confirmed a non-functioning pituitary adenoma.

Tumor cells were negative for immunolabelling for growth hormone, adrenocorticotropic hormone $(\mathrm{ACTH})$, prolactin, thyroid-stimulating hormone (TSH), luteinizing hormone, and follicle-stimulating hormone. On the other hand, neuroendocrine markers, CK8, CK18, and synaptophysin, were positive. (Fig. 3)

After postoperative care, the patient was discharged without any neurological complications. Upon discharge, hydrocortisone (10
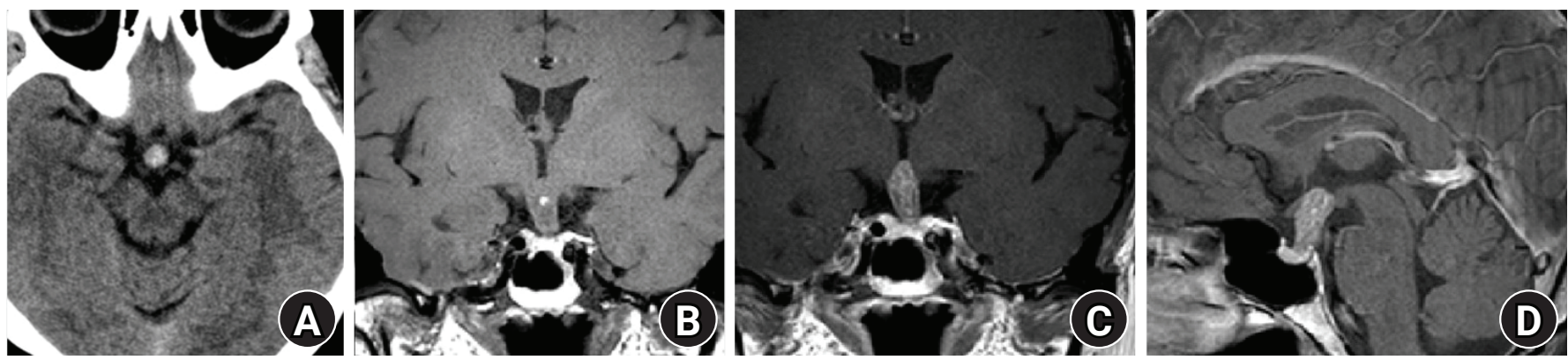

Fig. 1. Preoperative computed tomography (CT) and magnetic resonance image (MRI). (A) A high-density mass of 8 mm in diameter was shown in the pituitary stalk. (B) T1-weighted image showed a mass with moderate-intensity signals within the pituitary stalk. (C, D) The tumor was heterogeneously enhanced and bulging into the third ventricle.
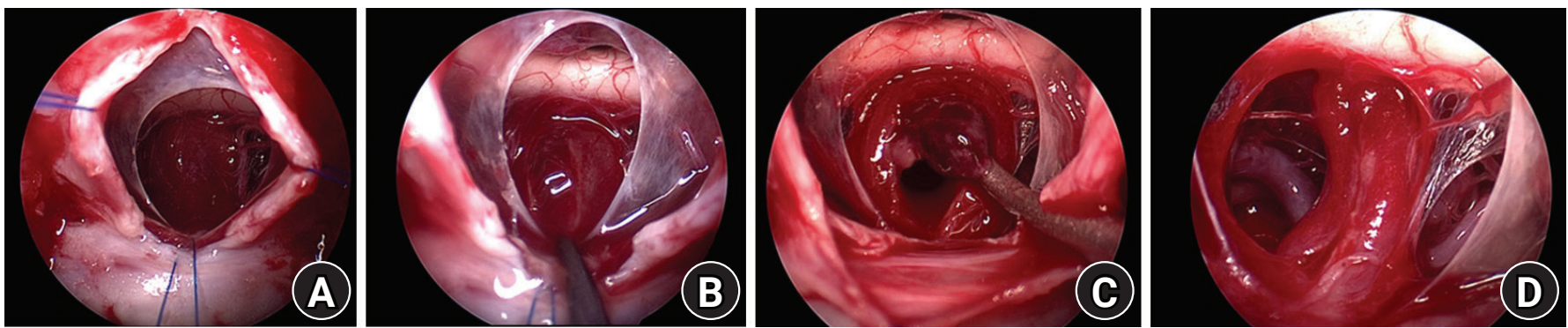

Fig. 2. Endoscopic operative view. (A) The pituitary stalk was thickened in diameter. (B) A vertical incision was made on the pituitary stalk. (C) Through the opening, the tumor was curetted and sucked out. (D) Structure of the pituitary stalk was preserved.
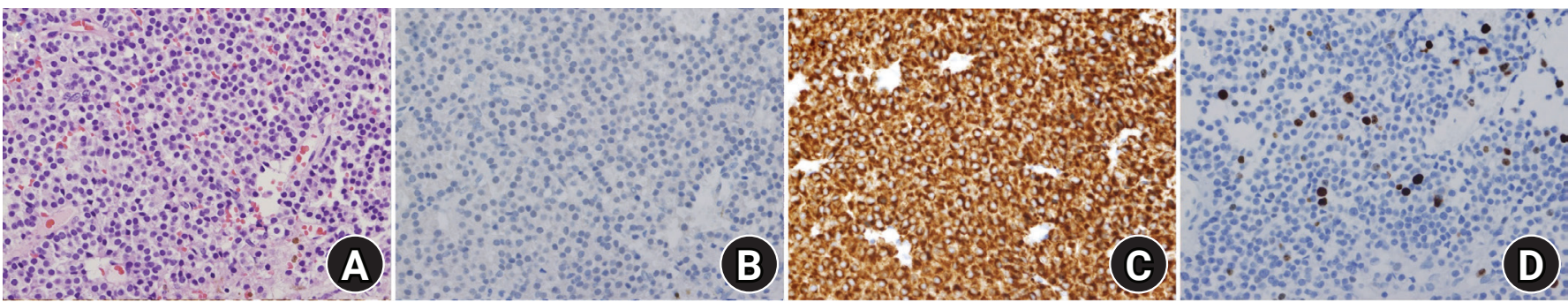

Fig. 3. Pathologic diagnosis confirmed pituitary adenoma. (A) Hematoxylin-eosin stain of the specimen $(\times 400)$. (B) Immunohistochemistry markers for growth hormone (GH), adrenocorticotropic hormone (ACTH), Prolactin, thyroid-stimulating hormone (TSH), luteinizing hormone (LH), follicle-stimulating hormone (FSH) were negative. (C) Synaptophysin, CK8 \&18 showed positive. (D)MIB-1 labeling index showed around $4 \%$. 
$\mathrm{mg} / 5 \mathrm{mg}$ ), levothyroxine (0.75 mg), and desmopressin (0.1 mg BID) were administered for hormone replacement. Hydrocortisone was discontinued after maintenance for six months. Levothyroxine was maintained for one year. (Fig. 4)

The patient is currently undergoing regular outpatient follow-up with preserved anterior pituitary function.

\section{DISCUSSION}

We report a case of pituitary adenoma confined in the pituitary stalk of a patient. Pituitary adenomas usually originate inside the sella turcica and extend to the suprasellar area. Rarely, it may originate from the stalk, but the majority of the masses protrude to the suprasellar area as it progresses. Thus, pituitary adenomas strictly confined to the pituitary stalk are extremely rare. An extensive literature review of PubMed revealed only six reported cases of pituitary adenomas within the pituitary stalk; all of which were functioning tumors. Tal reported a case of an ACTH-secreting tumor in the stalk in $1993^{7)}$. In 1997, Mason et al. reported 10 cases of ACTH-secreting ectopic pituitary adenomas that arose in the pituitary stalk; four of which originated and remained confined within the pituitary stalk ${ }^{8)}$. The most recent case of prolactinoma in the pituitary stalk was published in 2005 by Peker et $\mathrm{al}^{6)}$ (Table 1 ).

To the best of our knowledge, this is the first reported case of a non-functioning, pituitary stalk-confined adenoma without pituitary gland involvement. We did not initially aim for complete removal, but for biopsy. Through vertical incision on the stalk, we succeeded in completely removing the tumor while preserving the anatomy of the pituitary stalk.

\section{Anatomy}

The pituitary gland is anatomically divided into the anterior and posterior pituitary glands, also termed adenohypophysis and
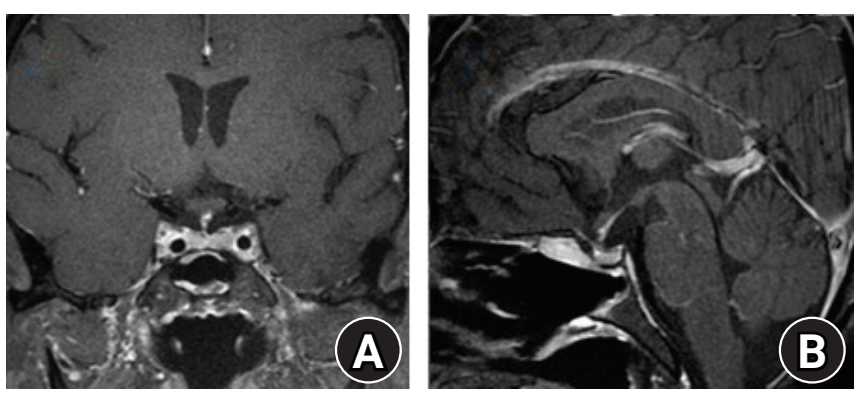

Fig. 4. The 2-year follow-up magnetic resonance images show completely resected tumor with no evidence of recurrence and anatomically preserved pituitary stalk in the (A) coronal and (B) sagittal section. neurohypophysis, respectively. The neurohypophysis is formed by the pars nervosa and the infundibular stalk. The pars nervosa acts as a repository for oxytocin and vasopressin, accounting for most of the volume of the posterior pituitary. The infundibular stalk connects the hypophyseal and hypothalamic systems. The anterior and posterior pituitary lobes are divided by a thin boundary, termed the pars intermedia. Most adenohypophysis cases are caused by the pars distalis, which stores ACTH, TSH, FSH, GH, $\mathrm{LH}$, and prolactin. The pars tuberalis is an extension of the pars distalis, encircling the infundibular stalk of the neurohypophy$\operatorname{sis}^{9,10)}$.

\section{Embryonic origin}

Embryologically, the neurohypophysis and adenohypophysis originate from the neuroectoderm and ectoderm, respectively. At the 4th week of gestation, the extracranial ectoderm of the primitive oral cavity is invaginated upward, forming the Rathke's pouch. The neuroectoderm forms an infundibular process that extends downward in contact with the invaginating ectoderm. At weeks 6-8, the Rathke's pouch pinches off, giving rise to the pars distalis, pars intermedia, and pars tuberalis. The pituitary formed resides within the mesoderm-derived sella turcica. The majority of pituitary adenomas, ectopic to the pituitary, originate from the remnant rest of the craniopharyngeal duct during the embryonic period $^{11)}$. Pituitary adenomas in the pituitary stalk not continuous to the gland are mostly considered to originate from the pars tuberalis $^{12,13)}$.

\section{Imaging study}

Pituitary adenomas on CT are usually iso-dense to gray matter and moderately enhanced by contrast dye. On MRI, the pituitary shows a low signal on T1WI and a high signal on T2WI. MRI with gadolinium shows mild-to-moderate enhancement ${ }^{11,14)}$; however, it is sometimes difficult to distinguish the ectopic form of pituitary adenoma from other juxta-sellar lesions such as craniopharyngio-

Table 1. Reported cases of ectopic pituitary adenoma in the pituitary stalk

\begin{tabular}{llcll}
\hline Case & \multicolumn{1}{c}{ Author, Year } & Size & $\begin{array}{c}\text { Secretory } \\
\text { function }\end{array}$ & \multicolumn{1}{c}{ Surgery } \\
\hline 1 & Tal A, 1993 $^{7)}$ & - & ACTH & - \\
2 & Mason RB et al., 1997 $^{8)}$ & $5 \mathrm{~mm}$ & ACTH & T.S.A. \\
3 & & $7 \mathrm{~mm}$ & ACTH & T.S.A. \\
4 & & $5 \mathrm{~mm}$ & ACTH & T.S.A. \\
5 & & $7 \mathrm{~mm}$ & ACTH & T.S.A. \\
6 & Peker S et al, 2005 $^{6)}$ & $1 \mathrm{~cm}$ & Prolactin & Pterional approach \\
\hline
\end{tabular}

T.S.A: Endonasal transsphenoidal approach, ACTH: Adrenocorticotropic hormone. 
ma, germ cell tumors, or neuro-epithelial tumors, even with a longterm follow-up of imaging studies ${ }^{12)}$.

As for our circumstance, there are several reported cases that mimicked other kinds of intracranial tumors on imaging and were later proven otherwise by pathologic confirmation ${ }^{15,16)}$. It has been debated that weighing hormone levels earlier could avoid unnecessary biopsy and/or surgical interventions ${ }^{11,17)}$. However, deeming surgery unnecessary may just be a conclusion by hindsight ${ }^{5)}$. In a comprehensive review published in 2019, Shuman et al. reviewed 85 cases of EPAs from 64 eligible publications out of 116 publications searched to date. According to the review, EPAs tend to be more active. Approximately $85 \%$ of tumors ( 72 out of 85 cases) were secretory; 50 cases were clinically functional and 35 were non-functional. This is a significantly higher ratio than that of pituitary adenomas. More importantly, in contrast to most pituitary tumors being considered benign, six out of 85 EPAs were reported to be malignant ${ }^{5}$. Furthermore, Mason et al. reported 10 cases of ACTH-secreting EPAs and found that only six cases showed corresponding MR with operative findings ${ }^{8)}$.

Considering that ectopic pituitary adenomas and pituitary adenomas in general have a slightly different pathophysiology, and that imaging studies can only provide a limited amount of information, the need for tissue confirmation is crucial for diagnosis. In our case of asymptomatic and ectopic pituitary adenoma, although follow-up observation was considered as an option, consequent growth to a symptomatic mass was one of the concerns. Furthermore, an initial imaging study suggested multiple differential diagnoses. Thus, preservation of the pituitary stalk, surgical biopsy, and removal were decided.

The transcranial approach is often considered when managing suprasellar lesions, in addition to trans-sellar, transdiaphragmatic, pterional, and trans-sphenoidal approaches ${ }^{11,18-19)}$. In our case, the trans-sphenoidal endonasal approach was selected.

\section{CONCLUSIONS}

Ectopic pituitary adenomas are rare, especially those that are nonfunctioning and confined within the pituitary stalk. Pituitary adenomas found in the suprasellar region sometimes require differential diagnoses of craniopharyngioma, germ cell tumors, or neuroepithelial tumors. When diagnosing juxta-sellar tumors, pituitary adenomas should be considered as a possibility; hormone profiles must be evaluated to avoid unnecessary surgery. Suprasellar lesions of EPAs may be safely removed via the endonasal route. When removing tumors within the pituitary stalk, if possible, the pituitary stalk and gland should be preserved.

\section{NOTES}

\section{Conflict of interest}

No potential conflict of interest relevant to this article was reported.

\section{REFERENCES}

1. Ezzat S, Asa SL, Couldwell WT, Barr CE, Dodge WE, Vance $\mathrm{ML}$, et al. The prevalence of pituitary adenomas: a systematic review. Cancer 2004;101:613-619.

2. Lucas JW, Bodach ME, Tumialan LM, Oyesiku NM, Patil CG, Litvack Z, et al. Congress of Neurological Surgeons Systematic Review and Evidence-Based Guideline on Primary Management of Patients With Nonfunctioning Pituitary Adenomas. Neurosurgery 2016;79:E533-E535.

3. Ortiz-Suarez H, Erickson DL. Pituitary adenomas of adolescents. J Neurosurg 1975;43:437-439.

4. Wu X, Wen M. CT finding of ectopic pituitary adenoma: case report and review of literature. Head Neck 2015;37:E120 E124.

5. Shuman W, Loewenstern J, Pai A, Bederson J, Shrivastava R. Variability in Clinical Presentation and Pathologic Implications of Ectopic Pituitary Tumors: Critical Review of Literature. World Neurosurg 2019;122:397-403.

6. Peker S, Sun I, Kurtkaya-Yapicier O, Elmaci I, Pamir MN. Ectopic pituitary adenoma located at the pituitary stalk. Case report. J Neurosurg Sci 2005;49:25-29.

7. Tal A. Cushing's disease caused by ectopic pituitary adenoma within the pituitary stalk. South Med J 1993;86:249-250.

8. Mason RB, Nieman LK, Doppman JL, Oldfield EH. Selective excision of adenomas originating in or extending into the pituitary stalk with preservation of pituitary function. J Neurosurg 1997;87:343-351.

9. Amar AP, Weiss MH. Pituitary anatomy and physiology. Neurosurg Clin N Am 2003;14:11-23.

10. Nakane PK. Classifications of anterior pituitary cell types with immunoenzyme histochemistry. J Histochem Cytochem 1970; 18:9-20.

11. Agely A, Okromelidze L, Vilanilam GK, Chaichana KL, Middlebrooks EH, Gupta V. Ectopic pituitary adenomas: common presentations of a rare entity. Pituitary 2019;22:339-343.

12. Yoneoka Y, Okada M, Watanabe N, Aoki S, Kakita A, Fujii Y. Ectopic pituitary null cell adenoma arising from the infundibulum in the third ventricle: A successful endonasal transsphenoidal resection after long-term follow-up MR imaging - A technical note. Interdisciplinary Neurosurgery 2017;10:122-125. 
13. Kohno M, Sasaki T, Narita Y, Teramoto A, Takakura K. Suprasellar ectopic pituitary adenoma--case report. Neurol Med Chir (Tokyo) 1994;34:538-542.

14. Yang BT, Chong VF, Wang ZC, Xian JF, Chen QH. Sphenoid sinus ectopic pituitary adenomas: CT and MRI findings. Br J Ra$\operatorname{diol} 2010 ; 83: 218-224$.

15. Karras CL, Abecassis IJ, Abecassis ZA, Adel JG, Bit-Ivan EN, Chandra RK, et al. Clival ectopic pituitary adenoma mimicking a chordoma: case report and review of the literature. Case Rep Neurol Med 2016;2016:8371697.

16. Hanaoka Y, Ogiwara T, Kakizawa Y, Nagm A, Seguchi T, Aoyama T, et al. Calcified ectopic TSH-secreting pituitary adenoma mimicking craniopharyngioma: a rare case report and literature review. Acta Neurochir (Wien) 2018;160:2001-2005.

17. Tsuda M, Takahashi S, Higano S, Kurihara N, Ikeda H, Sakamoto K. CT and MR imaging of craniopharyngioma. Eur Radiol 1997;7:464-469.

18. Tamaki N, Shirakuni T, Kokunai T, Matsumoto S, Fujimori T, Maeda S. Ectopic pituitary adenoma in the suprasellar cistern: case report. Surg Neurol 1991;35:389-394.

19. Hou L, Harshbarger T, Herrick MK, Tse V. Suprasellar adrenocorticotropic hormone-secreting ectopic pituitary adenoma: case report and literature review. Neurosurgery 2002;50:618625 . 